\title{
İntörn Doktorların Etik Duyarlık Düzeyleri ve Etkileyen Faktörler
}

\section{Moral Sensitivity of Interns and Affecting Factors}

\author{
Mustafa Levent Özgönül (ORCID: https://orcid.org/0000-0003-4135-1643) \\ Mustafa Daloğlul (ORCID: https://orcid.org/0000-0002-6315-4897) \\ Meltem Akdemir ${ }^{3}$ (ORCID: https://orcid.org/0000-0002-4855-6556) \\ Kamil Hakan Erengin ${ }^{3}$ (ORCID: https://orcid.org/0000-0002-8086-6474) \\ Yeşim Şenol (ORCID: https://orcid.org/0000-0002-7842-3041)
}

${ }^{1}$ Akdeniz Üniversitesi Tıp Fakültesi Tıp Eğitimi Anabilim Dalı Dumlupınar Bulvarı Kampus, Antalya

${ }^{2}$ Akdeniz Üniversitesi Tıp Fakültesi Tıp Tarihi ve Etik Anabilim Dalı Dumlupınar Bulvarı Kampus, Antalya

${ }^{3}$ Akdeniz Üniversitesi Tıp Fakültesi Halk Sağlığı Anabilim Dalı Dumlupınar Bulvarı Kampus, Antalya

\section{Sorumlu yazar:}

Dr. Öğr. Üyesi Mustafa Daloğlu

Akdeniz Üniversitesi Tıp Fakültesi Tıp Eğitimi Anabilim Dalı Dumlupınar Bulvarı Kampus 07059 Antalya

e-mail: drmustafadaloglu@gmail.com tel: +90 2422496164 GSM: +90 5063035464

Anahtar Sözcükler:

Ahlaki duyarlılık, intörn, doktor, etik

Keywords:

Moral sensitivity, intern,

physician, ethics

Gönderilme Tarihi

Submitted: 19.08 .2019

Kabul Tarihi

Accepted: 15.12.2019
ÖZET:

Amaç: Ahlaki duyarlılı̆̆ın gerçek hayattaki ahlaki karar verme sürecinde ilk adımı oluşturduğu düşünülmektedir. Etik anlamda yüklü bir uygulama olarak görülen sağlık alanında, hizmet sunucuların ahlaki duyarlılığının izlenmesi gerek hizmet kalitesi gerekse etik uygulama açısından önem arz etmektedir. Bu çalışmanın amacı intörn doktorlarda ahlaki duyarlılığın ve ahlaki duyarlılık ile ilişkili olabilecek faktörlerin saptanmasıdir.

Gereç ve Yöntem: Örneklem yöntemi kullanılmamış, araştırmaya katılmayı kabul eden 116 intörn doktor araştırmaya alınmıştır. Verilerin toplanması amacıyla, intörnlerin sosyodemografik özelliklerini içeren 12 soru ve 30 soru içeren Ahlaki Duyarlılık Anketi'nden oluşan veri toplama formu uygulanmıştır. Normal dağılım gösteren ölçek sonuçları

Künye: Daloğlu M, Özgönül M, Akdemir M, Erengin K, Şenol Y. Intörn Doktorların Etik Duyarlılık Düzeyleri ve Etkileyen Faktörler. Tip Eğitimi Dünyası. 2020;19(57):55-63 
için istatistiksel analiz Student $\mathrm{t}$ test testi ve ANOVA Testi ile yapıldi.

Bulgular: Çalışmaya katılan gönüllülerin Ahlaki Duyarlılık Anketi toplam puan ortalaması 89,14 olarak tespit edildi. Toplam puan, yarar sağlama ve oryantasyon alt ölçek puanlarına göre ahlaki duyarlılık düzeyi kadınlarda daha yüksek bulundu $(p<0,05)$. Toplam puan, otonomi, bütüncül yaklaşım, uygulama ve oryantasyon alt ölçek puanlarına göre gelir algısı yüksek kişilerin ahlaki duyarlılık düzeyleri daha yüksek bulundu $(\mathrm{p}<0,05)$. Araştırmanın bağımsız değişkenleri olan "fakülteye girmeden önce yaşanan yer", "mezun olunan okul türü”, “anne ve baba eğitim durumu", "hekim olma hayali", "tıp fakültesini seçme nedeni”, “ailede sağlık çalışanı olma durumu”, “ailede sakatlık olma durumu", "afet yaşama" ve "afete şahit olma" ile Ahlaki Duyarlılık Anketi ortalama puanı arasında istatistiksel olarak anlamlı bir ilişki bulunmamıştır ( $\mathrm{p}>0.05)$.

Sonuç: Bulgular, Ahlaki Duyarlılık Anketi ortalama puanları dikkate alındığında intörn doktorların ahlaki duyarlılıklarının üst orta düzeyde olduğunu göstermektedir. İntörnlerin ahlaki duyarlılığını kadın cinsiyet ve yüksek gelir düzeyi alg1sı olumlu yönde etkilemektedir. $\mathrm{Bu}$ etkinin sebeplerini aydınlatmak için izlem çalışmaları ve nitel araştırmalar planlanabilir.

\section{ABSTRACT:}

Background: Moral sensitivity is thought to be the first step in real-life moral decision-making. In the field of health, which is seen as an ethically loaded practice, monitoring the ethical sensitivity of service providers is essential both in terms of service quality and ethical practice. This study aimed to determine the moral sensitivity level and the factors that may be related to the moral sensitivity of interns.
Methods: A total of 116 volunteered intern doctors were included in the study without using a sampling method. In order to collect the data, a data collection form consisting of sociodemographic characteristics of the interns and Moral Sensitivity Questionaire (MSQ) was used. As the scores obtained from the scale showed normal distribution, Student's t-test was used for the comparison of two groups, and the ANOVA test was used for the comparison of three groups.

Results: The mean MSQ total score of the participants in the study was 89.14. The moral sensitivity level was higher in women in total score, benevolence, and orientation subscale scores $(p<0.05)$. Individuals with high-income perception have higher moral sensitivity level scores in total score, autonomy, meaning, rules, and orientation subscale scores ( $p$ $<0.05$ ). No significant relationship was found between the mean score of the Moral Sensitivity Questionnaire and the independent variables of the study such as "the area of residence before registering the faculty ", "the school graduated from", "education level of the parents", "dream of becoming a physician", "the reason of choosing medical faculty", "having a relative working as a healthcare provider", "having a disabled relative", "experience or witness disaster in the past".

Conclusion: When the average Moral Sensitivity Questionaire scores are taken into consideration, the findings show that the interns' moral sensitivity level is high-intermediate. The female gender and the perception of the high-income level positively affect the moral sensitivity of interns. Follow-up studies and qualitative research could be planned to clarify the reasons for this effect. 


\section{GíRIŞ}

Ahlaki duyarlılık (AD) ahlaki gelişim içinde bağımsız bir unsur olarak kabul edilmektedir. Gerçek hayattaki ahlaki karar verme sürecinde ilk adımı oluşturduğu düşünülmektedir. AD kavramı tarihte ilk olarak Shaftesbury Kontu Anthony Ashley Cooper tarafından, "bir kişinin doğru ve yanlış arasında ayrım yapmasını sağlayan ahlaki duygular" olarak tanımlanmıştır. $\mathrm{Bu}$ tanıma göre ahlaki duygular, doğru ve yanlış duygusu üzerinden gerekçelendirme ve merhamet duygusu ile biçimlenir (1). Merhamet duygusu, Tymieniecka tarafindan, insanın ontolojik anlayışında temel bir tema olarak kabul edilir. Ahlaki duyguları ise yaşamın ve kaderin anlamının bir bileşeni olarak vurgulamıştır. Tymieniecka'ya göre ahlak duygusu, bireyin tüm canlılara karşı merhametli bir duruş sergilemesini sağlar ve hayata ahlaki bir anlam kazandırır (2).

Kohlberg'in ahlaki gelişim teorisine dayanarak, Rest ve arkadaşları, ahlaki karar vermenin dört bileşenini ahlaki duyarlılık, ahlaki yargı, ahlaki motivasyon ve ahlaki karakter olarak vurgulamıştır (3-5).

$\mathrm{Bu}$ bileşenlerin ilki olan $\mathrm{AD}$, çatışma yüklü bir durumun içerdiği ahlaki değerlere "farkındalık" ve bu bağlam içinde kişinin kendi rolünün ve sorumluluğunun bilincinde olması olarak tanımlanabilir. AD, ahlaki bir çatışmayı saptamak için duygulara güvenmekle kalmaz, aynı zamanda bireyin kişisel deneyimleri ile kazandığı, ahlaki bir durumun önemini fark etme kapasitesini de gerektirir (6).

Sağlık hizmetlerinin sunumunda etik sorunlara kuramsal yaklaşım, günümüzde giderek daha çok tartışılmaktadır. Sağlık hizmeti doğass gereği, tıbbi tedavi ve bakıma ihtiyaç duyan bireylerin refahını sağlamak amacı ile verildiği için ahlaki bir girişim olarak kabul edilmektedir. Profesyonel bakım ve tedaviye ihtiyaç duyan bireylerin insan onurunu korumak ve rahatllk sağlamakla ilgili karar ve seçimler içermesi nedeniyle sağlık pratiği "etik anlamda yüklü bir uygulama" alanı olarak görülmektedir (7).

Sağlık hizmeti uygulamaları açısından ahlaki duyarlılık, ahlaki değerlere ilişkin bir çatışmayı tanıyabilme, hastanın hassas durumunu bağlamsal ve sezgisel olarak anlayabilme ve hasta adına alınan kararların etik sonuçlarını kavrayabilme becerisi olarak tanımlanabilir (6). Sağlık çalışanları çalışma koşulları gereği sıkça etik açıdan çelişkili durumlarla karşılaşmaktadır. Sağlık çalışanları, hizmet sunarken gereğini yerine getirememe duygusu veya kendi vicdanı ile çelişen eylemleri yürütmek zorunda kalmaları nedeniyle çelişen değerler ile iç içedirler. $\mathrm{Bu}$ durum sağlık hizmetini verirken duygusal zorluklar yaşamalarına neden olur (8-11).

Sağlık çalışanlarının etik açıdan uygun davranmalarını, etik olanı yapma konusunda istek veya motivasyon, etik konular hakkında bilgi, iletişim becerileri, ahlaki veya etik akıl yürütme becerisi ve bireyin etik meselelere olan inançları, tutumları ve duyarlıllğı gibi pek çok etmen belirlemektedir. Eğitsel olarak bu etmenler öğretilebilecek olanlar ve bireyin içsel özellikleri olarak iki ana gruba ayrılır (12).

Bireyin içsel özellikleri, diğerine göre ahlaki duyarlılık ile daha fazla ilişkilendirilebilir. $\mathrm{Bu}$ ilişkiyi ortaya koyabilecek mekanizmalar geliştirmek ve bireylerin olası olumlu ya da olumsuz ahlaki duyarlık özelliklerini belirleyip izlemek önemlidir. $\mathrm{Bu}$ alanda dünyada ve ülkemizde çeşitli çalışmalar bulunmaktadır (13-16).

Ülkemizdeki mezuniyet öncesine yönelik tüm eğitim uygulamalarında uluslararası tıp eğitimi ilke ve yaklaşımları doğrultusunda belirli bir standardın sağlanması amacı ile oluşturulmuş olan Ulusal Çekirdek Eğitim Programı(UÇEP), mezuniyet öncesi tıp eğitiminin amaçları 
arasında insani ve mesleki değer ve davranışlara yönelik yeterliklere yer vermiştir. Tutum hedefleri arasında, etik ve mesleki değerleri gözetme, sağlıkla ilgili tüm süreçlerde bu değerlere uygun davranış sergileme ve ortaya çıkan profesyonelliğe/etiğe aykırı durumlarla mücadele etme gibi hedefler açıkça belirtilmiştir (17).

$\mathrm{Bu}$ çalışmanın amacı intörn doktorlarda ahlaki duyarlılığın ve ahlaki duyarlılık ile ilişkili olabilecek faktörlerin saptanmasıdır.

\section{GEREÇ VE YÖNTEM}

Kesitsel düzeyde planlanmış bu araştırmanın evreni Akdeniz Üniversitesi Tıp Fakültesi (AÜTF) 2017-2018 eğitim-öğretim dönemindeki altıncı sınıf öğrencilerinden oluşmaktadır $(n=161)$. Örneklem yöntemi kullanılmamış, araştırmaya katılmayı kabul eden 116 intörn doktor araştırmaya alınmıştır. Katılım oranı \%72'dir. AÜTF'de birinci sinıfta kuramsal dersler, PDÖ'de etik öğrenme hedefleri ve 4. Sınıfta bir haftalık etik stajı bulunmaktadır. Her öğrenci için bu konu başlıkları zorunlu ders kapsamındadir.

Verilerin toplanması amacıyla, intörnlerin sosyodemografik özelliklerini içeren 12 soru ve 30 soru içeren Ahlaki Duyarlılık Anketi'nden oluşan veri toplama formu uygulanmıştır. Öğrenciler araştırma hakkında bilgilendirilmiş ve sözlü aydınlatılmış onam alınmıştır. Anket formu öğrencilere bir ders sırasında verilerek uygulanmıştır. Ahlaki Duyarlılık Anketi (ADA), etik duyarlılığı ölçmek amacıyla Kim Lützen tarafından geliştirilmiş olup, Karolinska Hemşirelik Enstitüsü'nde (14), öncelikle psikiyatri kliniğinde, daha sonra da diğer birimlerde çalışan hekim ve hemşirelere uygulanmıştır. Otuz ifadeden oluşan yedili likert tipte bir ölçektir. Ölçek maddeleri 1 puan (Tamamen katılıyorum),7 puan (Hiç katılmıyorum) arasında değerlendirilmektedir. Bir puan tamamen katılma yönünde yüksek duyarlılığı, 7 puan hiç katılmıyorum yönünde düşük duyarlılı̆̆ alınabilecek toplam puan 30-210 arasinda değişmektedir. Puanın yüksek olması etik açıdan düşük duyarlılığı, puanın düşük olması ise etik açıdan yüksek duyarlılığı göstermektedir. Anketin otonomi (otonomi ilkesine ve hastanın tercihlerine sayg1 duymayı yansitır), yarar sağlama (hasta bireyin yararını artırmaya yönelik eylemleri yansıtır), bütüncül yaklaşım (hem hastaya zarar vermeyecek, hem de hastanın bütünlüğünü koruyacak eylemleri ifade eder), çatışma (içsel bir etik çatışma deneyimini yansitır), uygulama (eyleme karar verme ve uygulamada etik boyutu düşünmeyi gösterir), oryantasyon (sağlık bakım profesyonellerinin hasta ile ilişkilerini etkileyecek eylemlerine yönelik ilgilerini yansıtır) olmak üzere altı alt boyutu vardır(18,19). Türkiye'de ölçeğin geçerlilik ve güvenirliği 2003 yılında Hale Tosun tarafından yapılmış olup, Cronbach alfa değeri 0.84 olarak saptanmıştır. Aynı çalışmada ölçeğin hekimlerde geçerlik ve güvenirliği de değerlendirilmiş ve hekimler için de etik duyarlılı̆̆ olduğu bildirilmiştir(19).

Veriler IBM SPSS 18.0 programı kullanılarak analiz edilmiştir. Sürekli değişkenlerin normal dağılıma uygunluğu Kolmogorov-Simirnov testi ile incelenmiştir. Çalışmada yer alan kategorik değişkenler frekans ve yüzde ile sürekli değişkenlerden normal dağılıma uyanlar ortalama ve standart sapma ile sunulmuştur. Ölçekten alınan puanlar normal dağılım gösterdikleri için değişkenlerin iki grup ortalama karşılaştırmalarında Student $\mathrm{t}$ test testi, üç grup karşılaştırmalarında ANOVA Testi kullanılmıştır. Farklılık gösteren grupların analizinde Tukey testi kullanılmıştır. Çalışmada 
istatistiksel anlamlılık düzeyi 0,05 olarak kabul edilmiştir.

\section{BULGULAR}

Çalışmaya katılan intörn doktorların \%54,3’ü kadın, \%69,8'i fakülteye girmeden önce ilde yaşamıştır ve \%82,8'i Fen ya da Anadolu lisesinden mezun olmuştur. \%45,7'sinin annesi, \%64,7'sinin ise babası üniversite mezunudur. Öğrencilerin \%49,2'sinin geliri giderine eşittir. Hekimlik mesleği \%58,6'sının hayalini kurduğu, gönlünde yatan meslektir ve \%34,5'inin ailesinde en az bir sağlık çalışanı bulunmaktadır. \%42,2'si hekimliği insancıl bir meslek olduğu için tercih etmiştir (Tablo 1).

Tablo 1: Katılımcıların demografik özellikleri ve bağımsız değișkenlerin dă̆ılımı.

\begin{tabular}{|c|c|c|}
\hline Özellik & $\begin{array}{c}n \\
(116)\end{array}$ & $\%$ \\
\hline \multicolumn{3}{|l|}{ Cinsiyet } \\
\hline Kadin & 63 & 54,3 \\
\hline Erkek & 53 & 45,7 \\
\hline \multicolumn{3}{|c|}{ Fakülteye girmeden önce yaşadığınız yer } \\
\hline İl & 81 & 69,8 \\
\hline İlçe & 24 & 20,7 \\
\hline Köy & 11 & 9,5 \\
\hline \multicolumn{3}{|l|}{ Mezun olduğunuz okul } \\
\hline Klasik Lise & 5 & 4,3 \\
\hline Fen-Anadolu Lisesi & 96 & 82,8 \\
\hline Ozel Lise & 8 & 6,9 \\
\hline Diğer & 7 & 6,0 \\
\hline \multicolumn{3}{|l|}{ Anne Eğitim Durumu } \\
\hline İlkokul mezunu & 31 & 26,7 \\
\hline Ortaokul-lise mezunu & 32 & 27,6 \\
\hline Üniversite mezunu & 53 & 45,7 \\
\hline \multicolumn{3}{|l|}{ Baba Eğitim Durumu } \\
\hline İlkokul mezunu & 15 & 12,9 \\
\hline Ortaokul-lise mezunu & 26 & 22,4 \\
\hline Ǘniversite mezunu & 75 & 64,7 \\
\hline \multicolumn{3}{|l|}{ Gelir Durumu } \\
\hline Gelir giderden fazla & 28 & 24,1 \\
\hline Gelir gidere eşit & 57 & 49,2 \\
\hline Gelir giderden az & 31 & 26,7 \\
\hline \multicolumn{3}{|c|}{ Hekim olmak hayalini kurduğunuz, gönlünüzde yatan meslek miydi? } \\
\hline Evet & 68 & 58,6 \\
\hline Hayır & 48 & 41,4 \\
\hline \multicolumn{3}{|l|}{ Ailede sağlık çalışanı var mı? } \\
\hline Evet & 40 & 34,5 \\
\hline Hayır & 76 & 65,5 \\
\hline \multicolumn{3}{|l|}{ Hekimlik mesleğini seçme nedeni* } \\
\hline İnsancillik & 49 & 42,2 \\
\hline Toplumsal sayginlik & 42 & 36,2 \\
\hline Ekonomik nedenler & 33 & 28,4 \\
\hline Bilimsellik & 23 & 19,8 \\
\hline Diğer (aile isteği, puan yüksekliği...) & 10 & 8,6 \\
\hline \multicolumn{3}{|c|}{$\begin{array}{l}\text { Aile bireylerinden birisi çok önemli boyutta ve/veya uzun süre tedavi olmayı gerektirecek bir hastalık } \\
\text { (yaşanan sakatlılı, engellilikler dâhil) geçirdi mi? }\end{array}$} \\
\hline Evet & 50 & 43,1 \\
\hline Hayır & 66 & 56,9 \\
\hline \multicolumn{3}{|c|}{ Deprem, yangın, sel, trafik kazası gibi hayatınızı etkilediğini düşündüğünüz büyük bir afet yaşadınız mı } \\
\hline Evet & 28 & 24,1 \\
\hline Hayır & 88 & 75,9 \\
\hline \multicolumn{3}{|c|}{ Yaşanan acılara bizzat şahit oldunuz mu? } \\
\hline Evet & 34 & 29,3 \\
\hline Hayir & 82 & 70,7 \\
\hline
\end{tabular}

* Birden fazla seçenek işaretlenmiştir 
Çalışmaya katılan dönem VI öğrencilerinin $\% 43,1$ 'inin aile bireylerinden birisi önemli boyutta ve/veya uzun süre tedavi olmay 1 gerektirecek bir hastalık geçirmiş, \%24,1' $\mathrm{i}$ büyük bir afet yaşamış, \%29,3'ü yaşanan acılara bizzat şahit olmuştur.

ADA toplam puanı ve alt ölçeklerden alınan puan ortalamaları Tablo 2 de gösterilmiştir.

Tablo 2: ADA alt ölçeklerinden alınan ortalama, minimum ve maksimum puanlar.

\begin{tabular}{|l|c|c|c|}
\hline Alt Boyutlar & Ortalama \pm SS & Minimum & Maksimum \\
\hline Otonomi & $20,79 \pm 5,30$ & 10 & 37 \\
\hline Yarar sağlama & $11,59 \pm 3,58$ & 4 & 21 \\
\hline Bütüncül yaklaşım & $12,46 \pm 3,49$ & 5 & 21 \\
\hline Çatıșma & $11,76 \pm 2,99$ & 5 & 20 \\
\hline Uygulama & $13,40 \pm 3,17$ & 4 & 21 \\
\hline Oryantasyon & $8,16 \pm 2,75$ & 4 & 14 \\
\hline Sinıfsız & $10,97 \pm 2,93$ & 3 & 21 \\
\hline Toplam & $89,14 \pm 14,12$ & 58 & 126 \\
\hline
\end{tabular}

Cinsiyet ile ADA arasında istatistiksel olarak anlamlı ilişki bulunmuştur (Tablo 3). Toplam puan, yarar sağlama ve oryantasyon alt ölçek puanları erkeklerde kadınlara göre daha yüksek bulunmuştur $(\mathrm{p}<0,05)$.

Gelir durumu ile ADA arasinda istatistiksel olarak anlamlı ilişki bulunmuştur (Tablo 3). Toplam puan, otonomi, bütüncül yaklaşım, uygulama ve oryantasyon alt ölçek puanları, geliri giderine eşit ya da az olan kişilerde, geliri fazla olanlara göre daha yüksek bulunmuştur $(\mathrm{p}<0,05)$.

Tablo 3: ADA toplam ortalama puan ve alt ölçek ortalama puanlartnun cinsiyet ve gelir algısı ile ilişkisi

\begin{tabular}{|c|c|c|c|c|c|c|c|c|}
\hline \multirow[t]{2}{*}{$\begin{array}{l}\text { Bağımsız } \\
\text { Değişken }\end{array}$} & & Otonomi & $\begin{array}{c}\text { Yarar } \\
\text { Sağlama }\end{array}$ & $\begin{array}{l}\text { Bütüncül } \\
\text { Yaklasım }\end{array}$ & Çatışma & Uygulama & Oryantasyon & Toplam \\
\hline & $n$ & Ort \pm SS & Ort \pm SS & Ort \pm SS & Ort \pm SS & Ort \pm SS & Ort \pm SS & Ort \pm SS \\
\hline \multicolumn{9}{|l|}{ Cinsiyet } \\
\hline Kadın & 63 & $20,14 \pm 5,24$ & $10,71 \pm 3,35$ & $12,03 \pm 3,29$ & $11,63 \pm 2,76$ & $13,21 \pm 3,09$ & $7,63 \pm 2,83$ & $86,51 \pm 13,52$ \\
\hline Erkek & 53 & $21,57 \pm 5,32$ & $12,64 \pm 3,58$ & $12,96 \pm 3,68$ & $11,91 \pm 3,28$ & $13,62 \pm 3,28$ & $8,79 \pm 2,54$ & $92,26 \pm 14,30$ \\
\hline \multicolumn{2}{|l|}{$p^{*}$} & 0,151 & 0,003 & 0,153 & 0,630 & 0,484 & 0,023 & 0,028 \\
\hline \multicolumn{9}{|c|}{ Gelir algısı } \\
\hline $\begin{array}{l}\text { Gelir } \\
\text { fazla }\end{array}$ & 28 & $18,50 \pm 4,80$ & $11,25 \pm 3,36$ & $10,86 \pm 2,86$ & $12,54 \pm 3,35$ & $12,18 \pm 2,82$ & $6,64 \pm 2,34$ & $83,07 \pm 11,21$ \\
\hline $\begin{array}{l}\text { Gelir } \\
\text { esit/az }\end{array}$ & 88 & $21,52 \pm 5,27$ & $11,70 \pm 3,66$ & $12,96 \pm 3,53$ & $11,51 \pm 2,85$ & $13,78 \pm 3,19$ & $8,65 \pm 2,70$ & $91,07 \pm 14,45$ \\
\hline \multicolumn{2}{|l|}{$\mathrm{P}^{* * 1 \%}$} & 0,008 & 0,560 & 0,005 & 0,115 & 0,019 & 0,001 & 0,008 \\
\hline
\end{tabular}

$\mathrm{Bu}$ araştırmanın diğer bağımsız değişkenleri, fakülteye girmeden önce yaşanan yer, mezun olunan okul türü, anne ve baba eğitim durumu, hekim olma hayali, tıp fakültesini seçme nedeni, ailede sağlık çalışanı olma durumu, ailede sakatlık olma durumu, afet yaşama ve afete şahit olma şeklinde sıralanmaktadır (Tablo 1). $\mathrm{Bu}$ bağımsız değişkenler ile ADA ortalama puanı arasında anlamlı bir ilişki bulunmamıştır $(\mathrm{p}>0.05)$. 


\section{TARTIŞMA}

Bireyin içsel özellikleri ile daha fazla ilişkili olmakla beraber, etik karar verme süreçlerinde önemli rol oynayan $\mathrm{AD}$, tıp eğitimi programında yeralması gereken başlıklardandır. Çalışmamızın tıp fakültesi eğitimini tamamlamak üzere olan intörn doktorlar ile yapılmış olması, eğitim süreci sonunda $\mathrm{AD}$ konusunda hedeflenen çıktıların değerlendirmesine olanak sağlamıştır. Çalışma grubunun ADA'dan aldığ 1 ortalama puanın üst orta seviyede olduğu saptanmıştır. ADA ilk olarak hemşirelerde ahlaki duyarlılığı ölçmek üzere geliştirilmiş olması nedeniyle literatürde hekimler üzerinde yapılan çalışmalar sınırlıdır. Mezuniyet öncesi tıp fakültesi öğrencilerinde yapılmış çalışmaya rastlanmamıştır. Hekim ve hemşire gruplarında yapılmış olan güncel çalışmalardaki ortalama puanlar ile karşılaştırıldığında çalışmamızda elde edilen ortalamala puanın benzer veya daha yüksek olduğu izlenmiştir(18,20-22). Fakültemizde etik öğrenme hedefleri birinci dönemden itibaren belirli siklıkta program boyunca devam etmektedir. Eğitim programında etik konu başlıklarına dördüncü dönemde klinik stajlardan ayrı bir staj kurulu olarak yer verilmektedir. İntörnlerin ahlaki duyarlılığının tatmin edici düzeyde olması eğitim programında etik konu başlıklarına ayrıntılı değinilmesinden kaynaklanması olasıdır. Literatürde yer alan pek çok müdahale çalışması, etik eğitimi almanın $\mathrm{AD}$ üzerine anlamlı etkisi olduğunu göstermektedir(20,21,23-25).

İntörnlerde ADA'y1 etkileyen faktörler incelendiğinde cinsiyet ve gelir algısının puanlarda anlamlı bir farklılık yarattığ izlenmiştir. Kadın öğrencilerin erkek öğrencilere göre daha olumlu ahlakiduyarlılık düzeyine sahip olduğu görülmüsstür. Literatürde sağlık alanında yapılmış olan pek çok çalışmada katılımcıların normal dağılımı sağlanamadığından cinsiyetin ahlaki duyarll1lı̆ga etkisi istatistiki olarak test edilememiştir(20,24,26). Çalışmamız bulgularına benzer şekilde kadın cinsiyetin ahlaki duyarlığa olumlu etkisini gösteren çalışmalar mevcuttur (27). Çalışmamızda ADA'nın "Oryantasyon" $(p=0,023)$ ve
"Yarar sağlama" $(p=0,003)$ alt ölçeklerinde cinsiyet açısından anlamlı farklar izlenmiştir. Lützen ve ark. hekimlerin de dahil edildiği çalışmalarında, cinsiyetin yalnızca "Bütüncül Yaklaşım" alt ölçeğinde anlamlı farka sebep olduğunu bildirmişlerdir(18). Ahlaki gelişim felsefe ve psikoloji alanlarının ilgi çeken araştırma konularındandır. Cinsiyetin ahlak üzerine etkisi ile ilişkili çelişen teoriler ve çalışmalar bulunmaktadır. Kohlberg tarafindan 1969'da tanımlanan Ahlaki Gelişim Teorisi bu alanda geniş çevrelerce kabul görmüş̧ür(28). Ancak ilerleyen y1llarda Gilligan, Kohlberg'in teorisinin yanlış yapılandırılmış olduğunu ve kadınları ahlak anlamında eksik olarak tanımladığını belirtmiştir(29). Çelişen teoriler ve çalışmalar 1şığında, You ve ark. AD düzeyi tespiti yapan 19 çalışmayı dahil ettikleri meta analizde, kadınların erkeklere göre ahlaki duyarlılığının anlamlı düzeyde yüksek olduğunu belirtmiştir(30). Aynı çalışma tespit edilen bu farka eğitim düzeyinin etkisi olmadığını göstermiştir(30).

Düşük gelir algısı olan grubun ADA ortalama puanları yüksek gelir algısı olan gruba göre yüksek bulunmuştur. $\mathrm{Bu}$ bulgu, gelir alg1s1 yüksek gönüllülerin ahlaki duyarlılık düzeylerinin anlamlı derecede yüksek olduğunu göstermektedir $(\mathrm{p}<0.05)$. Literatürde gelir algıs1 ile ahlaki duyarlılık düzeyi arasındaki ilişkiyi inceleyen yalnızca bir yayına rastlanılmış olup bu çalışmada istatistiksel bir anlamlılık saptanamamıştır(24).

$\mathrm{Bu}$ çalışmanın diğer bağımsız değişkenleri olan fakülteye girmeden önce yaşanan yer, mezun olunan okul türü, anne ve baba eğitim durumu, hekim olma hayali, tıp fakültesini seçme nedeni, ailede sağlık çalışanı olma durumu, ailede sakatlik olma durumu, afet yaşama ve afete şahit olma ile ADA ortalama puanı arasında anlamlı bir ilişsi bulunmamıştır. Literatürde, katılımcı yaşının $(25,26,31)$ ve mesleki tecrübenin $(16,31,32)$ ahlaki duyarlılığa etkili faktörler olduğunu belirten çalışmalar mevcuttur. Çalışmamızın intörn doktorlar üzerinde yapılmış olması nedeniyle katılımcı yaşları ve mesleki tecrübeleri genel olarak 
eşit veya yakındır. $\mathrm{Bu}$ nedenle çalışmamızda katılımcı yaşı ve mesleki tecrübe bağımsız değişken olarak incelenmemiştir. Oğuzhan ve ark. çalışmalarında evli olma durumu ahlaki duyarlılığı etkileyen bir faktör olarak tespit edilmiştir (33). Araştırma grubunu mezuniyet öncesi öğrencilerin oluşturması nedeniyle katılımcıların medeni halinin ahlaki duyarlılığa etkisi araştırılmamıştır.

$\mathrm{Bu}$ çalışmanın güçlü ve zayıf yönleri bulunmaktadır. Çalışmanın evrenine ulaşma oranı yüksektir. Çalışmanın güvenirliliği iyi olmakla birlikte çalışma tek bir merkezde anket yöntemi ile yapılmıştır. $\mathrm{Bu}$ nedenle çalışma sonuçları yalnızca kendi fakültemiz için genellenebilir. Daha net sonuçların ortaya çıkartılması için izlem çalışmalarının planlanması önerilmektedir.

\section{SONUÇ}

AÜTF intörnlerinin ADA ortalama puanları dikkate alındığında ahlaki duyarlılıkları üst orta düzeydedir. İntörnlerin ahlaki duyarlılığını kadın cinsiyet ve yüksek gelir düzeyi algısı olumlu yönde etkilemektedir. Fakülteye girmeden önce yaşanan yer, mezun olunan okul türü, anne ve baba eğitim durumu, hekim olma hayali, tıp fakültesini seçme nedeni, ailede sağlık çalışanı olma durumu, ailede sakatlık olma durumu, afet yaşama ve afete şahit olma değişkenlerinin ahlaki duyarlılığa etkisinin bulunmadığ saptanmıştır.

\section{KAYNAKLAR}

1. Lützén $\mathrm{K}$, Dahlqvist $\mathrm{V}$, Eriksson $\mathrm{S}$, Norberg A. Developing the concept of moral sensitivity in health care practice. Nurs Ethics. 2006;13(2):187-96

2. Tymieniecka AT. The moral sense in the communal significance of life: Investigations in phenomenological praxeology: psychiatric therapeutics, medical ethics and social praxis within the life and communal world. Dordrecht: Reidel; 1986. 4-44 p.
3. Rest JR, Narvaez D. Moral Development in the Professions Psychology and Applied Ethics. 1st Editio. New York: Psychology Press; 1994.

4. Rest JR, Narvaez D, Thoma SJ, Bebeau MJ. A Neo-Kohlbergian approach to morality research. J Moral Educ. 2000;29(4):381-95

5. Kohlberg L, Hersh RH. Moral Development: A Review of the Theory. Theory Into Practice. 1977;16(2):53-9

6. Lützén K. Moral Sensing and Ideological Conflict: Aspects of the Therapeutic Relationship in Psychiatric Nursing. Scand J Caring Sci. 1990;4(2):69-76

7. Gastmans C. A fundamental ethical approach to nursing: Some proposals for ethics education. Nurs Ethics. 2002;9(5):494-507

8. Söderberg A, Gilje F, Norberg A. Transforming desolation into consolation: The meaning of being in situations of ethical difficulty in intensive care. Nurs Ethics. 1999;6(5):357-73

9. Sørlie V, Jansson L, Norberg A. The meaning of being in ethically difficult care situations in paediatric care as narrated by female Registered Nurses. Scand J Caring Sci. 2003;17(3):285-92

10. Sørlie V, Kihlgren AL, Kihlgren M. Meeting ethical challenges in acute care work as narrated by enrolled nurses. Nursing Ethics. 2004;11(2):179-88

11. Cronqvist A, Theorell T, Burns T, Lützén K. Caring about - Caring for: Moral obligations and work responsibilities in intensive care nursing. Nurs Ethics. 2004;11(1):63-76

12. Lowe M, Kerridge I, Bore M, Munro D, Powis D. It is possible to assess the "ethics" of medical school applicants? J Med Ethics. 2001;27(6):404-8 
13. Lützén K, Evertzon M, Nordin C. Moral sensitivity in psychiatric practice. Nurs Ethics. 1997;4(6):472-81

14. Çetin M, Cimen M. Assessing a group of physicians' ethical sensitivity in Turkey. Iran J Public Health. 2011;40(3):89-97.

15. Aydın Y, Dikmen Y, Kalkan SC. Ebelik Öğrencilerinin Hasta Bakim Uygulamalarinda Etik Duyarliliklarinin İncelenmesi. J Contemp Med. 2017;7(2):168-168.

16. Yılmaz D, Düzgün F, Uzelli Yılmaz D, Akın Korhan E, Dikmen Y. Examination of Ethical Sensitivity and Related Factors of Nurses in Internal Clinics: An Example of University Hospital. DEUHFED. 2018;11(2):157-63.

17. Mezuniyet Öncesi T1p Eğitimi Ulusal Çekirdek Eğitim Programı-2014.

18. Lützén K, Johansson A, Nordström G. Moral sensitivity: Some differences between nurses and physicians. Nurs Ethics. 2000;7(6):520-30

19. Tosun H. Ahlaki Duyarlılık Anketi (ADA): Geçerlik ve güvenirlik çalışması. J Contemp Med. 2018;8(4):316-21

20. Lee HL, Huang SH, Huang CM. Evaluating the effect of three teaching strategies on student nurses' moral sensitivity. Nurs Ethics. 2017;24(6):732-43

21. Park M, Kjervik D, Crandell J, Oermann $\mathrm{MH}$. The relationship of ethics education to moral sensitivity and moral reasoning skills of nursing students. Nurs Ethics. 2012;19(4):56880

22. Borhani F, Abbaszadeh A, Mohamadi E, Ghasemi E, Hoseinabad-Farahani MJ. Moral sensitivity and moral distress in Iranian critical care nurses. Nurs Ethics. 2017;24(4):474-82

23. Yeom HA, Ahn SH, Kim SJ. Effects of ethics education on moral sensitivity of nursing students. Nurs Ethics. 2017; 24(6):644-52

24. Baykara ZG, Demir SG, Yaman S. The effect of ethics training on students recognizing ethical violations and developing moral sensitivity. Nurs Ethics. 2015; 22(6):661-75

25. Üzar Özçetin YS, Hiçdurmaz D. The Related Factors of Moral Sensitivity in Nursing Students. DEUHFED. 2018;11(3):209-17.

26. Tazegün A, Çelebioğlu A. Ethical Sensitivity Levels of Pediatric Nurses and The Factors Affecting This Sensitivity. J Dr Behcet Uz Child s Hosp. 2016;6(2):97-102

27. Tuvesson H, Lützén K. Demographic factors associated with moral sensitivity among nursing students. Nurs Ethics. 2017;24(7):847-55

28. Kohlberg L, Kramer R. Continuities and discontinuities in childhood and adult moral development. Hum Dev. 1969;12(2):93-120

29. Gilligan C. In a Different Voice: Psychological Theory and Women's Development. Cambridge, MA: Harvard University Press; 1982.

30. You D, Maeda Y, Bebeau MJ. Gender differences in moral sensitivity: A meta-analysis. Ethics Behav. 2011;21(4):263-82

31. Lützén K, Blom T, Ewalds-Kvist B, Winch S. Moral stress, moral climate and moral sensitivity among psychiatric professionals. Nurs Ethics. 2010;17(2):213-24

32. Başak T, Uzun Ş, Arslan F. Investigation of the moral sensibility of intensive care nurses. Gulhane Med J. 2010; 52(2):76-81

33. Oguzhan G, Aydın GZ, Bölükbaşı FB. Determination of nursing moral sensitivity: A state hospital example. Sağlık Akad Derg. 2019;6(2):91-9. 